\title{
Impact of a community-based diabetes self-management program on key metabolic parameters
}

\author{
Courtney JOHNSON, Janelle F. RUISINGER, Jessica BATES, Brian J. BARNES.

\begin{abstract}
${ }^{*}$
Objective: Characterize the impact of a pharmacist-led diabetes self-management program on three key metabolic parameters: glycosylated hemoglobin ( $\mathrm{HbA} 1 \mathrm{c})$, low-density lipoprotein cholesterol (LDL-C), and mean arterial blood pressure (MAP) among employee health program participants.

Methods: A self-insured company in the Kansas City metropolitan area began offering a pharmacist-led diabetes self-management program to eligible company employees and their dependents in 2008. A retrospective pre-post analysis was conducted to determine if the program affected key metabolic parameters in participants by determining mean change after one year of participation.

Results: Among 183 program participants, 65 participants met inclusion criteria. All three key metabolic parameters were significantly reduced from baseline to one year of program participation: $\mathrm{HbA} 1 \mathrm{c}$ decreased from $8.1 \%$ to $7.3 \%$ ( $p=0.007$ ); LDL-C decreased from $108.3 \mathrm{mg} / \mathrm{dL}$ to $96.4 \mathrm{mg} / \mathrm{dL}(p=0.009)$; and MAP decreased from 96.1 to $92.3 \mathrm{~mm} \mathrm{Hg}(p=0.005)$.

Conclusions: The pharmacist-led diabetes selfmanagement program demonstrated significant reductions in HbA1c, LDL-C, and MAP from baseline to one year of program participation. Improvements were statistically significant and clinically relevant for each parameter. Previous studies indicate these reductions may cause reduced overall healthcare costs.
\end{abstract}

Keywords: Diabetes Mellitus; Pharmaceutical Services; Patient Education as Topic; Longitudinal Studies; United States

*Courtney JOHNSON. PharmD. Pharmacy Project Specialist. Balls Food Stores-Price Chopper Pharmacy. Overland Park, KS (United States). courtney.johnson@ballsfoods.com Janelle F. RUISINGER. PharmD. Community Pharmacy Residency Director, School of Pharmacy, University of Kansas. Kansas City, KS (United States).

jruisinger@kumc.edu

Jessica BATES. PharmD. Pharmacist-in-Charge, Balls Food Stores-Price Chopper Pharmacy. Overland Park, KS (United States). jessica.bates@ballsfoods.com Brian J. BARNES. PharmD, MS. Associate Dean for Academic Affairs, School of Pharmacy, University of Kansas. Kansas City, KS (United States). bbarnes@ku.edu

\section{INTRODUCTION}

Chronic diseases, including diabetes, are a widespread health problem. Diabetes affects approximately 25.8 million Americans and ranks as the seventh leading cause of death in the United States. $^{1}$ The impact of diabetes includes both physical complications and significant financial burdens. Adults with diabetes have a two to four times greater risk for stroke than those without diabetes, and are two to four times more likely to die from heart disease. ${ }^{1}$ Medical expenses for people with diabetes are more than two times higher than for those without diabetes. ${ }^{1}$ Employers bear the economic burden both directly through employerprovided health insurance and indirectly through higher rates of sick days, disability, and injury. Employee wellness programs including pharmacistdirected services may help reduce long-term complications and costs associated with diabetes. ${ }^{2}$

Community pharmacists have provided diabetes disease state management services for over a decade. These services include pharmacist coaching, patient education, implementing evidence-based diabetes care guidelines, and teaching patient self-management strategies. ${ }^{2,3}$ Prior studies indicate community-based diabetes management programs provide clinical improvement on glycosylated hemoglobin ( $\mathrm{HbA} 1 \mathrm{c})$, low-density lipoprotein cholesterol (LDL-C), and blood pressure (BP). ${ }^{2,3}$ These previous analyses lack information regarding the provision of these programs in a local grocery store chain setting. Additionally, to our knowledge, most of the previous analyses included data from over 100 participants. ${ }^{2-}$ 8 This study demonstrates that even with fewer than 100 patients $(n=65)$, pharmacists can make not only a statistically significant but also a clinically significant impact on diabetes management. Pharmacists in this setting are well positioned to help patients with diabetes achieve glycemic control and prevent long-term complications.

The objective was to assess the impact of a pharmacist-led diabetes self-management program provided to insured individuals with diabetes in a local chain grocery store. Impact was defined as mean change from baseline to one year in three key metabolic parameters including $\mathrm{HbA} 1 \mathrm{c}$, LDL-C, and mean arterial blood pressure (MAP).

\section{METHODS}

This study was conducted at Balls Food Stores, a self-insured employer in the Kansas City 
metropolitan area. The employer operates 27 grocery stores with 20 pharmacies. The employer began offering a pharmacist-led diabetes selfmanagement program to eligible company employees and their dependents in 2008. Eligibility for the program was based on a Type 1 or Type 2 diabetes diagnosis from medical claims data. Program participation incentives included: reduced health insurance premiums, a free blood glucose meter, reduced copays on lancets, waived copays for generic glucose-lowering agents, and 50\% discounted copays on needles, syringes, pen needles, and brand name glucose-lowering agents.

Employees and dependents who participated in the pharmacist-led diabetes self-management program enrolled voluntarily and completed a program participation agreement detailing program goals, patient responsibility, confidentiality, and right to withdraw from the program. Participants consented to release medical information, allowing pharmacists to correspond with patients' providers. Providers were informed of their patient's program participation and were encouraged to share their treatment goals with the pharmacists.

The program consisted of one-on-one visits between the patient and an assigned clinical pharmacist averaging six 30-minute visits each year. Visits were scheduled on an individual basis to meet the needs of the patient and did not occur at rigidly defined intervals. During each visit, the pharmacist provided patient-specific education regarding numerous diabetes related topics including pathology, healthy lifestyle habits, medication use and adherence, progress toward appropriate therapeutic goals, and self-monitoring. Each visit also included a brief assessment to determine the patient's level of understanding on the education topic. Clinical measurements such as blood pressure, blood sugar, and weight were also collected by the pharmacist during visits. Following each visit, the pharmacist corresponded with the patients' provider via a faxed summary note that included subjective and objective findings, the education topic covered at the visit, and any recommended changes to drug therapy. The pharmacist made treatment recommendations based on clinical practice guidelines or referred patients to their provider for further assessment, laboratory tests, or other needs. The provider remained responsible for changes in medication therapy.

The pharmacist-led diabetes self-management program focused on intense patient self-care education, frequent patient monitoring, goal planning, and structured patient accountability. The program curriculum was based on the American Pharmacists Association (APhA) Foundation's psychometrically validated Patient SelfManagement Program (PSMP) for Diabetes that stemmed from the Asheville Project. ${ }^{4}$ Knowledge and skills assessments were utilized to coach patients toward optimal diabetes management. A performance checklist was utilized to assess ongoing self-management, which included preventative care measures consistent with diabetes care guidelines. All clinical pharmacists in the pharmacist-led diabetes self-management program were residency-trained and completed a diabetes certificate training program offered through APhA.

This study was a retrospective pre-post analysis. Participants who enrolled in the pharmacist-led diabetes self-management program between November 1, 2008 and December 31, 2012 were eligible for inclusion if they were 18 years or older, had at least two documented program visits with a clinical pharmacist, and had both baseline and one year data for $\mathrm{HbA} 1 \mathrm{c}$, LDL-C, and MAP. Baseline was defined as three months prior to or one month following the first program visit with a clinical pharmacist. One year was defined as 10 to 14 months following the first program visit with a clinical pharmacist.

Following approval by the University of Kansas Human Subjects Committee, de-identified data were collected for general demographics and metabolic parameters from a web-based documentation system. Clinical values were collected from patients' laboratory reports made available by providers and also from physical assessments completed by clinical pharmacists at each one-on-one visit.

The clinical outcomes measured were the mean changes from baseline to one year for $\mathrm{HbA1c}$, LDL$C$, and MAP among program participants. Previously, pharmacist-led diabetes selfmanagement publications individually evaluated systolic and diastolic BP as separate variables. ${ }^{2,4,7,8}$ However, we chose to simply evaluate MAP in place of SBP and DBP for two reasons. First, MAP is an accurate composite assessment of $B P$, calculated by the equation: $M A P=[(2 \quad x$ diastolic)+systolic] / 3. Secondly, the statistical comparison of a composite measure of blood pressure, rather than its individual components, reduces the type I statistical error rate which may result from evaluation of multiple outcomes among the same cohort. Since the data was normally distributed, paired t tests were used to analyze the difference between baseline and one year mean changes for each of the three key metabolic parameters. The a priori alpha level of significance was reduced from $p<0.05$ to $p<0.01$ to reduce the risk of committing a type I error since three statistical comparisons were utilized.

\section{RESULTS}

A total of 183 patients participated in the pharmacist-led diabetes self-management program between 2008 and 2012. Of these patients, 118 were excluded from analysis: three were less than 18 years old, 25 did not participate for one year, and 90 were missing baseline and/or one-year data. Therefore, 65 patients were included in the analysis. Demographics are summarized in Table 1. Of the 65 patients, the majority were female with an average age of 54 years.

At the end of one year, statistically significant improvements were found for program participants in $\mathrm{HbA} 1 \mathrm{c}, \mathrm{LDL}-\mathrm{C}$, and MAP (Table 2). Mean HbA1c 


\begin{tabular}{|l|c|}
\hline \multicolumn{2}{|l|}{$\begin{array}{l}\text { Table 1. Demographics of diabetes self-management } \\
\text { program participants ( } \mathrm{n}=65)\end{array}$} \\
\hline \multicolumn{1}{|c|}{ Characteristic } & Baseline \\
\hline Mean Age, years (SD) & $53.5(9.2)$ \\
\hline Female, no. (\%) & $36(55 \%)$ \\
\hline Tobacco Use, no. (\%) & $16(25 \%)$ \\
\hline Mean Body Mass Index, $\mathrm{kg} / \mathrm{m}^{2}(\mathrm{SD})$ & $33.7(7.1)$ \\
\hline
\end{tabular}

decreased $0.7 \%$ during program participation but remained above the American Diabetes Association (ADA) guideline goal of $<7 \%$ at the end of one year. ${ }^{9}$ Mean LDL-C concentrations also decreased and were below the National Cholesterol Education Program Adult Treatment Panel III guideline goal of $<100 \mathrm{mg} / \mathrm{dL}$. ${ }^{10} \mathrm{BP}$ reductions were also noted as MAP decreased $4.6 \mathrm{mmHg}$ at the end of one year. The baseline MAP values reflect systolic and diastolic BP readings achieving the ADA guideline goal of $<130 / 80 \mathrm{~mm} \mathrm{Hg}$, whereas the one year MAP values confirm BP readings decreased to $<120 / 80$ $\mathrm{mm} \mathrm{Hg}{ }^{9}$

\section{DISCUSSION}

This analysis shows that $\mathrm{HbA} 1 \mathrm{c}$ concentrations, the primary metabolic parameter for diabetes, improved following one year of participation in the pharmacistled diabetes self-management program. Our study demonstrated a statistically and clinically significant reduction in $\mathrm{HbA} 1 \mathrm{c}$ of $0.7 \%$. This is consistent with data from the Diabetes Ten City Challenge and Project IMPACT: Diabetes which established a mean $\mathrm{HbA} 1 \mathrm{c}$ decrease of $0.4 \%$ and $0.8 \%$ respectively after one year of participation in a pharmacist-managed program. ${ }^{2,10}$ Previous research established that any reduction in $\mathrm{HbA} 1 \mathrm{c}$ correlates with a decreased risk of complications making the improvement demonstrated in this study clinically relevant. ${ }^{11}$

Additionally, our study showed an $11.9 \mathrm{mg} / \mathrm{dL}$ LDL$C$ reduction after one year, which is similar to the $11.4 \mathrm{mg} / \mathrm{dL}$ reduction demonstrated in the PAMPERED study that also showed the benefit of collaborative diabetes management with a clinical pharmacist. $^{13}$ If mean systolic and diastolic BP changes from the PSMP for Diabetes are used to calculate MAP, our study also demonstrated a similar impact on BP control by achieving a $4.6 \mathrm{~mm}$ $\mathrm{Hg}$ reduction compared to $3.2 \mathrm{~mm} \mathrm{Hg}$ seen in the PSMP. $^{4}$

The primary focus of the pharmacist-led diabetes self-management program was to equip patients to better care for their chronic disease by partnering with them in the self-care process. Patients met regularly with their clinical pharmacist to have questions answered, learn self-management strategies, and be held accountable for meeting personal diabetes-related goals. Whenever possible, patients maintained visits with the same clinical pharmacist for the duration of their program participation.

Collaboration between providers and the clinical pharmacists was another integral element in the program's success. Providers were encouraged to share their treatment plan with the patient's clinical pharmacist. Additionally, the clinical pharmacists faxed brief summary notes and recommendations after each visit to the patients' provider.

A study by Wagner et al. demonstrated overall health cost savings within one to two years with a persistent $\mathrm{HbA} 1 \mathrm{c}$ reduction. ${ }^{14}$ Thus, our program may have resulted in total health care cost savings since a significant reduction was seen in $\mathrm{HbA} 1 \mathrm{c}$ at the end of one year of participation. As a result of the clinical improvements associated with this program, another local self-insured employer has contracted with Balls Food Stores to incorporate this pharmacist-led diabetes self-management program into their health plan.

Limitations of this study include: the observational nature lacking randomization or a control group and the small sample size $(n=65)$. Also, this pharmacistled diabetes self-management program was offered as a voluntary health benefit so participants may be healthier and more motivated than those who declined to participate. Furthermore, economic and humanistic data has not been collected. Future studies should include assessment of economic and humanistic data to provide further support for employer-based collaborative diabetes management programs utilizing community pharmacists. Study duration was also a limitation since patients were only analyzed for their first year of program participation. Many participants continued the program so analysis of data beyond one year may be useful in determining the persistence of improvements seen.

\section{CONCLUSIONS}

Patients with diabetes who met one-on-one with a clinical pharmacist as part of an employersponsored pharmacist-led diabetes selfmanagement program achieved significant improvements in HbA1c, LDL-C, and MAP at the end of one year compared to baseline data. Reductions in each of the three metabolic parameters were statistically and clinically significant, although $\mathrm{HbA} 1 \mathrm{c}$ values remained above the ADA guideline goal following one year of program participation. ${ }^{9}$ Based on results from previous studies, these reductions are expected to correspond with a decline in projected total direct patient medical costs. ${ }^{2}$

\begin{tabular}{|c|c|c|c|c|}
\hline \multicolumn{6}{|c|}{ Table 2. Change in Key Metabolic Parameters from Baseline to One Year of Program Participation ( $\mathrm{n}=65)$} \\
\hline & $\begin{array}{c}\text { Baseline Value } \\
\text { Mean (SD) }\end{array}$ & $\begin{array}{c}\text { One Year Value } \\
\text { Mean (SD) }\end{array}$ & $\begin{array}{c}\text { Change from Baseline } \\
\text { Mean (95\% Cl) }\end{array}$ & $\mathrm{p}^{\mathrm{a}}$ \\
\hline $\mathrm{HbA1c}(\%)$ & $8.1(2.4)$ & $7.3(1.4)$ & $-0.7(0.2: 1.2)$ & 0.007 \\
\hline $\mathrm{LDL}-\mathrm{C}(\mathrm{mg} / \mathrm{dL})$ & $108.3(36.4)$ & $96.4(27.6)$ & $-11.9(3.1: 20.7)$ & 0.009 \\
\hline MAP $(\mathrm{mm} \mathrm{Hg})$ & $96.1(13.0)$ & $92.3(12.2)$ & $-4.6(1.8: 7.5)$ & 0.002 \\
\hline
\end{tabular}

Abbreviations used: $\mathrm{Cl}$, confidence interval; HbA1c, glycosylated hemoglobin; LDL-C, low-density lipoprotein cholesterol; MAP, mean arterial blood pressure.

${ }^{a} \mathrm{p}$-value determined by two-tailed $t$ tests for paired data assessing the mean change with alpha set at $<0.01$ 


\section{CONFLICT OF INTEREST}

The authors declare no conflicts of interests or financial interests in any product or service mentioned in this article, including grants, employment, gifts, stock holdings, or honoraria.

\section{Funding: None}

Disclaimer: The views expressed in this article are my own and not an official position of the University of Kansas School of Pharmacy or Balls Food Stores.

Previous Presentations: American Pharmacists Association Annual Meeting March 2013, Los Angeles, CA; Midwest Pharmacy Residency Conference, May 2013, Omaha, NE.

\section{IMPACTO SOBRE LOS PARÁMETROS METABÓLICOS CLAVE DE UN PROGRAMA DE AUTO-MANEJO DE LA DIABETES EN FARMACIA COMUNITARIA}

\section{RESUMEN}

Objetivo: Caracterizar el impacto de un programa farmacéutico de auto-manejo de la diabetes entre os empelados participantes en un programa de salud sobre tres parámetros metabólicos claves: hemoglobina glicosilada (HbA1c), colesterol de baja densidad (LDLC), and media de presión arterial (MAP).

Métodos: Una empresa auto-asegurada del área metropolitana de Kansas City comenzó a ofrecer un programa farmacéutico de automanejo de la diabetes a trabajadores elegibles y sus familiares en 2008. Se realizó un análisis retrospectivo pre-post para determinar si el programa afectó a los parámetros metabólicos clave de los participantes determinando el cambio medio tras un años de participación.

Resultados: De los 183 participantes del programa, 65 cumplieron los criterios de inclusión. Los tres parámetros metabólicos clave se redujeron significativamente desde el inicio hasta un año de participación en el programa: HbA1c disminuyó de $8,1 \%$ a 7,3\% ( disminuyó de 108,3 mg/dL a 96,4 mg/dL ( $\mathrm{p}=0,009) ; \mathrm{y}$ MAP disminuyó de 96,1 a 92,3 mm Hg ( $\mathrm{p}=0,005)$.

Concusiones: El programa farmacéutico de auto-manejo de la diabetes demostró reducciones significativas en HbAlc, LDL-C, y MAP entre su inicio y un año de participación. Las mejoras fueron estadísticamente significativas y clínicamente relevantes para todos los parámetros. Estudios previos indican que estas reducciones pueden producir ahorro de costes sanitarios generales.

Palabras clave: Diabetes Mellitus; Servicios Farmacéuticos; Educación del Paciente como Asunto; Estudios Longitudinales; Estados Unidos

\section{References}

1. Centers for Disease Control and Prevention. National diabetes fact sheet: national estimates and general information on diabetes and prediabetes in the United States. 2011; http://www.cdc.gov/diabetes/pubs/factsheet11.htm (accessed November 15, 2012).

2. Fera T, Bluml BM, Ellis WM. Diabetes Ten City Challenge: final economic and clinical results. J Am Pharm Assoc (2003). 2009;49(3):383-391. doi: 10.1331/JAPhA.2009.09015

3. Cranor CW, Bunting BA, Christensen DB. The Asheville Project: long-term clinical and economic outcomes of a community pharmacy diabetes care program. J Am Pharm Assoc (Wash). 2003;43(2):173-184.

4. Garrett DG, Bluml BM. Patient self-management program for diabetes: first-year clinical, humanistic, and economic outcomes. J Am Pharm Assoc. 2005;45(2):130-137.

5. Bluml BM. "Project IMPACT: Diabetes" Care Model Improves Health Outcomes in Underserved Populations in 25 Communities with a High Incidence of Diabetes. Am Health Drug Benefits. 2013;6(9):560-561.

6. Chung N, Rascati K, Lopez D, Jokerst J, Garza A. Impact of a clinical pharmacy program on changes in hemoglobin a1c, diabetes-related hospitalizations, and diabetes-related emergency department visits for patients with diabetes in an underserved population. J Manag Care Pharm. 2014;20(9):914-919.

7. Iyer R, Coderre P, McKelvey T, Cooper J, Berger J, Moore E, Kushner M. An employer-based, pharmacist intervention model for patients with type 2 diabetes. Am J Health Syst Pharm. 2010;67(4):312-316. doi: 10.2146/ajhp090047

8. Scott DM, Boyd ST, Stephan M, Augustine SC, Reardon TP. Outcomes of pharmacist-managed diabetes care services in a community health center. Am J Health Syst Pharm. 2006;63(21):2116-2122.

9. American Diabetes Association. Standards of medical care in diabetes--2013. Diabetes Care. 2013;36(Suppl 1):S11S66. doi: $10.2337 / \mathrm{dc} 13-\mathrm{S} 011$

10. National Cholesterol Education Program (NCEP) Expert Panel on Detection, Evaluation, and Treatment of High Blood Cholesterol in Adults (Adult Treatment Panel III). Third Report of the National Cholesterol Education Program (NCEP) Expert Panel on Detection, Evaluation, and Treatment of High Blood Cholesterol in Adults (Adult Treatment Panel III) final report. Circulation. 2002;106(25):3143-3421.

11. Bluml BM, Watson LL, Skelton JB, Manolakis PG, Brock KA. Improving outcomes for diverse populations disproportionately affected by diabetes: Final results of Project IMPACT: Diabetes. J Am Pharm Assoc. 2014;54(5):477485. doi: 10.1331/JAPhA.2014.13240

12. American Diabetes Association. Implications of the diabetes control and complications trial. Diabetes Care. 2003;26(Suppl 1):S25-S27.

13. Jacobs M, Sherry PS, Taylor LM, Amato M, Tataronis GR, Cushing G. Pharmacist Assisted Medication Program Enhancing the Regulation of Diabetes (PAMPERED) study. J Am Pharm Assoc. 2012;52(5):613-621

14. Wagner EH, Sandhu N, Newton KM, McCulloch DK, Ramsey SD, Grothaus LC. Effect of improved glycemic control on health care costs and utilization. JAMA. 2001;285(2):182-189. 